\title{
Pathogenicity of a Very Virulent Strain of Marek's Disease Herpesvirus Cloned as Infectious Bacterial Artificial Chromosomes
}

\author{
Lorraine P. Smith, ${ }^{1}$ Lawrence J. Petherbridge, ${ }^{1}$ Susan J. Baigent, ${ }^{1}$ \\ Jennifer Simpson, ${ }^{2}$ and Venugopal Nair ${ }^{1}$ \\ ${ }^{1}$ Avian Infectious Disease Programme, Institute for Animal Health, Compton, Newbury, Berkshire RG20 7NN, UK \\ ${ }^{2}$ Bioimaging Group, Institute for Animal Health, Ash Road, Pirbright, Surrey GU24 ONF, UK \\ Correspondence should be addressed to Venugopal Nair, venu.gopal@bbsrc.ac.uk
}

Received 7 August 2010; Accepted 27 September 2010

Academic Editor: Gregory Tannock

Copyright ( $) 2011$ Lorraine P. Smith et al. This is an open access article distributed under the Creative Commons Attribution License, which permits unrestricted use, distribution, and reproduction in any medium, provided the original work is properly cited.

\begin{abstract}
Bacterial artificial chromosome (BAC) vectors containing the full-length genomes of several herpesviruses have been used widely as tools to enable functional studies of viral genes. Marek's disease viruses (MDVs) are highly oncogenic alphaherpesviruses that induce rapid-onset T-cell lymphomas in chickens. Oncogenic strains of MDV reconstituted from BAC clones have been used to examine the role of viral genes in inducing tumours. Past studies have demonstrated continuous increase in virulence of MDV strains. We have previously reported on the UK isolate C12/130 that showed increased virulence features including lymphoid organ atrophy and enhanced tropism for the central nervous system. Here we report the construction of the BAC clones (pC12/130) of this strain. Chickens were infected with viruses reconstituted from the pC12/130 clones along with the wild-type virus for the comparison of the pathogenic properties. Our studies show that BAC-derived viruses induced disease similar to the wild-type virus, though there were differences in the levels of pathogenicity between individual viruses. Generation of BAC clones that differ in the potential to induce cytolytic disease provide the opportunity to identify the molecular determinants of increased virulence by direct sequence analysis as well as by using reverse genetics approaches on the infectious BAC clones.
\end{abstract}

\section{Introduction}

Herpesviruses are major pathogens associated with a number of diseases both in man and animals. Since herpesviruses have large genomes, between $120 \mathrm{kbp}-230 \mathrm{kbp}$ in size, the manipulation of the viral genomes to identify the molecular determinants and mechanisms of pathogenesis is difficult. However, the use of bacterial artificial chromosome (BAC) as vectors for cloning the large DNA virus genomes as a single-copy mini-F plasmid [1] has opened new avenues for carrying out reverse genetics approaches for understanding herpesvirus gene functions [2]. Marek's disease virus (MDV), a member of the genus Mardivirus, is a highly contagious alphaherpesvirus that induces Marek's disease (MD), characterised predominantly by a rapid-onset T-cell lymphoma in poultry. BAC technology was first applied to clone the genome of an attenuated serotype $1 \mathrm{MDV}$ strain 584Ap80C [3]. Since then, the genomes of a number of virulent and attenuated Mardiviruses have been cloned as infectious BAC clones [4-11] and used to identify the determinants of virulence as well as for expression of foreign genes [12-14].

MD is controlled primarily by the widespread use of a number of live attenuated vaccines since the 1970s. These include the antigenically related herpesvirus of turkey (HVT), MDV-2 strain SB-1, as well as the widely used CVI988 (Rispens) strain [15]. Although vaccines have been generally very successful in reducing the losses from the disease, vaccination strategy has not been very effective in preventing the evolution of viruses towards greater virulence [16-18]. This has necessitated the periodic introduction of different generations of vaccines to keep up with continuing 
increase in virulence of the MDV and a number of different pathotypes classified as vMDV, vvMDV, and vv+MDV pathotypes have been isolated $[15,19]$. Even though the molecular determinants associated with the increasing virulence of these pathotypes are yet to be identified, the genome sequence of these viral pathotypes has indicated changes in parts of their genomes $[20,21]$. Although the analysis of the sequence changes are helpful, functional studies with mutant viruses are required to identify the determinants of altered virulence of these MDV pathotypes. Cloning of the genomes of virulent MDV pathotypes as infectious BAC can facilitate the application of reverse genetics approaches to generate mutant viruses and to identify the functional determinants associated with the altered pathological characteristics of these viruses.

MDV strain C12/130 was isolated from a field outbreak of HVT-vaccinated broilers in 1991 from the United Kingdom. The disease it produces has an unusually severe cytolytic phase, with enlargement of spleen, regression of the primary lymphoid organs, Bursa of Fabricius and thymus, and very late tumours $[22,23]$. Two similar strains were isolated in Europe at the time, MR36 and MR48 [24]; these strains produced high early mortality and destruction of the lymphoid tissues [22]. Monocytosis is a feature of the $\mathrm{C} 12 / 130$ strain, and neurological disease has also been associated with mononuclear cell infiltration of the meninges from 6 to 10 days post infection. Birds infected with C12/130 strain have increased cell death of the infected B-cells and macrophages during the acute cytolytic phase [25]. This virus shares characteristics with $\mathrm{vv}+\mathrm{MDV}$ as described by Witter, but cannot be classified as such due to the lack of formal pathotyping studies [16].

In the current study, we report on the cloning of the hypervirulent UK MDV strain C12/130 to elucidate some of its unique biological properties. Wild-type virus populations are often considered to exist as a collection of individual viruses that make up the quasispecies [21, 26], and we have previously shown that the cloning of the CVI988 (Rispens) virus as BAC clones has enabled the identification of individual clones with molecular differences in their genomes [5]. Based on these observations, we hypothesised that the wild-type C12/130 virus population is comprised of a pool of viruses, and cloning the genomes of these viruses as BAC clones would allow us to examine the behaviour of individual viruses in the pool. This paper describes the in vitro and in vivo characteristics of viruses derived from five individual $\mathrm{BAC}$ clones of $\mathrm{C} 12 / 130$ virus.

\section{Materials and Methods}

2.1. Cells and Viruses. Primary or secondary chicken embryo fibroblasts (CEFs) maintained in Medium 199 (Gibco BRL), supplemented with 10\% Tryptose phosphate broth and $5 \%$ foetal calf serum were used to grow up the virus stocks. C12/130 virus isolated from splenocytes prepared from infected Rhode Island Red (RIR) chicks at 6 days postinfection (dpi) were used as the source of DNA for the generation of the recombinant $\mathrm{BAC}$ clones.
2.2. Construction of the BAC Clones. The procedures for the construction of the BAC clones were carried out essentially as described [27-29]. Briefly, the pDS-pHA1 vector, which contains the mini-F plasmid flanked by 2.1 and $3.0 \mathrm{kbp}$ homologous regions surrounding the US2 gene of MDV1 , was used for the construction of the BAC clones. The C12/130 viral DNA for the generation of BAC was extracted from infected CEFs using standard phenol chloroform extraction methods. Primary CEFs (seeded at $1.3 \times 10^{6}$ cells per well) in a six well plate were used for the cotransfection of the C12/130 virus-infected DNA and the pDS-pHA1 vector DNA using the calcium phosphate precipitation method. Approximately $1.25 \mu \mathrm{g}$ per well of the pDS-pHA1 DNA was cotransfected with varying volumes $(1 \mu \mathrm{L}, 2.5 \mu \mathrm{L}$ and $5 \mu \mathrm{L})$ of C12/130 DNA. After cotransfection of the C12-130 DNA with the pDSpHAI vector, the cells were passaged four times in selection medium containing mycophenolic acid, xanthine, and hypoxanthine. Genomic DNA was then extracted from the selected cells and electroporated into E coli DH10B cells. DNA extracts from chloramphenicol-resistant colonies were further analysed by restriction digestion, followed by transfection of $1 \mu \mathrm{g}$ of DNA into CEFs, and monitored for viral infectivity. Of several clones tested, five clones that produced MDV plaques on CEFs after transfection of the BAC DNA were used to prepare viral stocks following two further passages.

2.3. Analysis of the Recombinant C12/130 BAC DNA. The integrity of the recombinant BAC constructs was examined by molecular analyses of the DNA from the individual C12/130 BAC clones by agarose gel electrophoresis of DNA samples digested with BamHI, EcoRI, and HindIII. DNA samples from wild-type $\mathrm{C} 12 / 130$ virus, the five recombinant C12/130 BAC clones, and the previously reported pRB-1B5 [27] were also analysed by Southern hybridisation [30] using Digoxigenin-labelled probes (Roche Diagnostics, East Sussex, United Kingdom). The DIG-labelled probes specific for $g p t$ and Meq genes were prepared by PCR using $g p t$ probes (5'-ATGAGCGAAAAATACATCGTC- $3^{\prime}$ and $5^{\prime}$ TTAGCGACCGGAGATTGGCGG- $3^{\prime}$ ) and the meq probes (5'-GCACTCTAGAGGTGTAAAGAGATGTCTCAG- $3^{\prime}$ and 5'-TAACTCGAGGAGAAGAAACATGGGGCATAG-3'), respectively.

2.4. Animal Experiments. All chickens used in the experiments were specific pathogen free (SPF), free of maternal antibodies to MDV, and hatched and reared in the Experimental Animal House with HEPA filtered rooms, one group per room. All the experiments were carried out under British Home Office regulations, by trained staff holding a Home Office Personal Licence for the various procedures. Birds were killed by a schedule I method once the clinical endpoint defined by Home Office regulations was reached.

Experiment 1 was designed to examine the genetic susceptibility of different lines of chickens to infection with wild-type C12/130 virus. The five lines of chickens used in this experiment included the congenic inbred line $\mathrm{N}$ (MHC $\left.\mathrm{B}^{21 / 21}\right)$, line $\mathrm{P}\left(\mathrm{MHC} \mathrm{B}^{19 / 19}\right)$, line 6 , line $7\left(\mathrm{MHC} \mathrm{B}^{2 / 2}\right)$, and 
the outbred Rhode Island Red (RIR) line. Ten birds of each line were infected with 1,000 plaque forming units (pfu) of wild-type $\mathrm{C} 12 / 130$ virus stocks via the intra-abdominal route at one day of age and observed for 60 days for the development of clinical signs. Birds that developed clinical signs during or at the end of the experiment were examined post mortem for gross or histopathological lesions.

Experiment 2 was designed to examine the differences between the recombinant viruses reconstituted from the individual BAC clones in their ability to induce early cytolytic disease. The experiment was carried out in one-day-old outbred RIR chickens inoculated with $1,000 \mathrm{pfu}$ of wildtype $\mathrm{C} 12 / 130$, and the reconstituted recombinant viruses as described in Experiment 1, 12 per group, each was housed in separate rooms with two sentinels. The cytolytic phase of infection was allowed to proceed, and the birds were observed for 12 days. All the birds that developed clinical signs and reached the clinical endpoint (birds that appeared distressed, that is, off their legs, not eating or drinking, with paralysis, twisted neck, or visible tumours) were killed, and the survival rates calculated from the incidence of MD based on gross or histopathological lesions with GraphPad Prism (Version 5) using the product limit method of Kaplan and Meier, and curves were compared using the log rank test, equivalent to the Mantel-Cox test [31].

2.5. Immunofluorescence Detection of Viral Antigens in Infected Tissues. Tissues were taken from freshly killed birds and fixed in $4 \%$ paraformaldehyde for two hours then transferred to PBS at $4^{\circ} \mathrm{C}$. Tissue sections were cut at $70 \mu \mathrm{m}$ using a VT1000S vibrating microtome (Leica Microsystems, Milton Keynes, United Kingdom). Sections were permeabilised in $0.1 \%$ Triton X100 (Sigma) for one hour at room temperature and blocked overnight in blocking buffer (PBS supplemented with $0.05 \%$ sodium azide, $0.5 \%$ bovine serum albumin, and $\mathrm{PBS} / \mathrm{BSA}$ ). Sections were incubated with primary monoclonal antibody BD1 recognising MDV-encoded protein pp38 [32] and species-specific Alexa Fluor 568-conjugated secondary antibodies. The sections were washed in PBS and cellular nuclei stained with DAPI $(1: 5,000)$ for 40 minutes. The sections were mounted onto glass slides using Vectashield mounting medium, and coverslips were sealed with nail varnish before visualisation by confocal microscopy (Leica Microsystems).

\section{Results and Discussion}

3.1. Cloning of the Genomes of Hypervirulent C12/130 MDV as Infectious BAC Clones. Cotransfection of CEFs with wildtype C12/130 viral DNA and the pDS-pHA1 DNA and subsequent growth in the presence of selection medium showed evidence of viral infection, demonstrating the growth of recombinant viruses. Electroporation of the DNA extracted from the CEFs into E. coli DH10B cells generated a number of chloramphenicol-resistant colonies. The ability of the high molecular weight DNA prepared from these cultures to reconstitute infectious virus was tested by DNA transfection into CEFs. These experiments showed that five of the DNA extracts were able to produce infectious virus 3-4 days after transfection, demonstrating the reconstitution of the virus from the transfected DNA. The size and morphology of the plaques produced by the wild-type and the recombinant C12/130 were indistinguishable (not shown). These infectious $\mathrm{BAC}$ clones were designated $\mathrm{pC} 12 / 130-3,-5,-8$, -10 , and -15 , respectively. Pulse field gel electrophoresis of the BamHI, EcoRI, and HindIII digested DNA samples from these clones demonstrated a pattern similar to that of the pRB-1B5 clone (data not shown), demonstrating that the BAC clones did not have any major deletions or genomic rearrangements. This further demonstrated the infectivity of these clones. Southern blot hybridization of the EcoRI-digested DNA of these clones with the gpt probe demonstrated a single major hybridizing band $(\sim 1.7 \mathrm{~kb})$ in all the $\mathrm{pC} 12 / 130$ clones, at an identical position to that in the pRB-1B5 (Figure 1(a)). Demonstration of identical bands in the DNA samples from the reconstituted viruses of two of the BAC clones, that is, $\mathrm{pC} 12 / 130-10$ and $\mathrm{pC} 12 / 130-15$, showed that the mini-F plasmid is carried in the genome of the reconstituted viruses. The specificity of the probe was confirmed by the absence of signals in the DNA prepared from the wild-type C12/130 virus. Hybridization of the same blot with the Meq probe detected the meq gene $(\sim 2.2 \mathrm{~kb})$ in all the BAC clones and the wild-type and reconstituted C12/130 viruses (Figure $1(\mathrm{~b})$ ).

\subsection{Dynamics of C12/130 Virus Infection in Different Genetic} Lines. One of the distinguishing features of some of the recent hypervirulent MDV strains, such as the C12/130 strain, is the ability to induce rapid-onset cytolytic disease characterized by marked atrophy of the lymphoid organs and high mortality [33]. Previous studies have also shown that birds infected with C12/130 virus developed marked monocytosis and infiltration into the brain [34-36], possibly accounting for the high levels of mortality. Interestingly, the involvement of the brain has been shown to be associated with a number of the hypervirulent strains $[37,38]$. The association between occurrences of neurological syndromes and the increasing virulence of MDV strains has led to the demonstration that neuropathotyping can be used to classify the virulence of MDV pathotypes [39]. In the present study, we first examined whether the wild-type C12/130 virus did indeed induce acute cytolytic disease and neurological symptoms and whether the genetic background of the chickens affected the susceptibility to the disease. The incidence of the disease, calculated from the percent survival during the 60day experimental period, showed that the outbred RIR birds were highly susceptible to the disease, with more than 90 per cent of the birds developing acute cytolytic disease within the first 10 days after infection (Figure 2(a)). The study of genetically susceptible line $\mathrm{P}$ and line 7 demonstrated around $40 \%$ incidence of MD during the same period, with the latter showing high incidence of the disease towards the end of the experimental period. The two genetically resistant lines $\mathrm{N}$ and 6 displayed only mild levels of MD, demonstrating that the genetic resistance mechanisms of these lines also function against hypervirulent strains. 


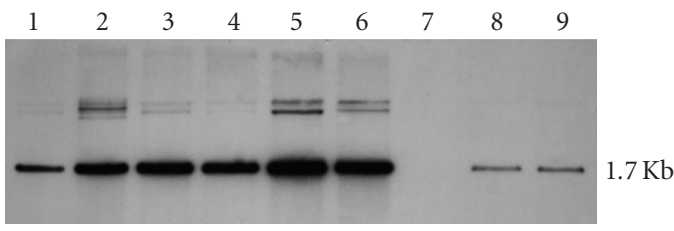

(a)

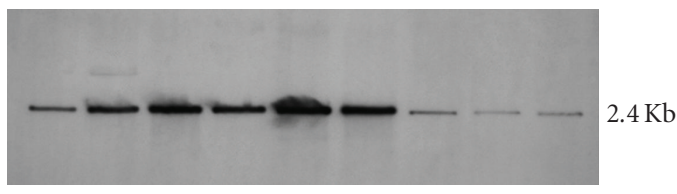

(b)

FIGURE 1: Southern hybridisation of wild-type and BAC clones of C12/130. Southern blots of the EcoRI-digested DNA from the wildtype $\mathrm{C} 12 / 130$ virus and the BAC clones sequentially hybridized with digoxigenin-labelled (a) $g p t$ and (b) meq probe. While the $g p t$ probe detects the specific band in all BAC-derived viral DNA, but not in the wild-type C12/130 virus, meq probe gives positive signals in all the lanes. Band sizes are shown on the right hand side. Lanes (1) pRB-1B5 [4], (2) pC12-130-3, (3) pC12-130-5, (4) pC12-130-8, (5) pC12-130-10, (6) pC12-130-15, (7) wild-type C12-130, (8) virus derived from pC12-130-10, and (9) pC12-130-15.

3.3. BAC-Derived C12/130 Viruses Can Induce Cytolytic Disease. Having demonstrated that the RIR chicks are highly susceptible to the early cytolytic disease induced by $\mathrm{C} 12 / 130$ virus, we wanted to examine whether the recombinant $\mathrm{C} 12 / 130$ viruses reconstituted from the individual infectious BAC clones induced cytolytic disease and neurological lesions akin to the wild-type virus from which they were derived. For this, we carried out experimental infection of highly susceptible one-day-old RIR chickens with C12/130 viruses reconstituted from five infectious BAC clones together with the wild-type virus. Groups of birds infected with 1,000 pfu of each of the viruses were observed during the 12-day experimental period for the development of cytolytic disease. As demonstrated in the previous experiment, more than 90 per cent of the birds infected with the wild-type C12/130 virus developed the early cytolytic disease during this period (Figure 2(b)). However, viruses reconstituted from the five individual BAC clones presented a range of differences in early cytolytic disease development. $\mathrm{C} 12 / 130$ virus reconstituted from the BAC clone 10 induced the highest level of the disease in more than 50 per cent of the birds, with viruses from the clones $-3,-5$, and -8 developing slightly lower levels of the disease. In contrast, virus derived from the $\mathrm{pC} 12 / 130-15$ clone did not produce any disease during the experimental period (Figure 2(b)). The clinical signs of birds developing acute cytolytic disease were indistinguishable between wild-type and reconstituted viruses and included ruffled feathers, crouched appearance, and neurological signs. As expected, none of the birds had any evidence of tumors although varying levels of atrophy of the lymphoid organs thymus and bursa of Fabricius were visible in many of the birds that developed the cytolytic disease. Of the sentinel birds, blood samples were examined

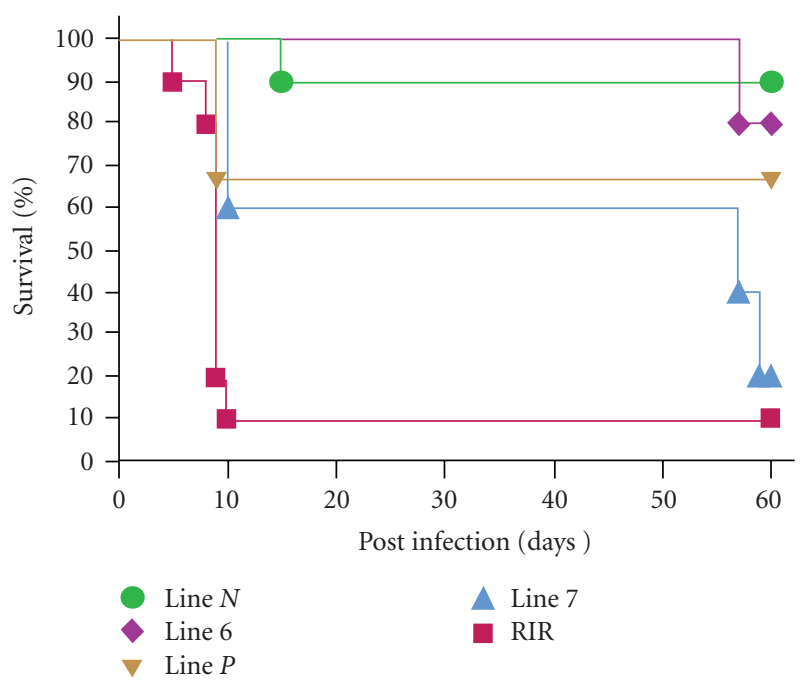

(a)

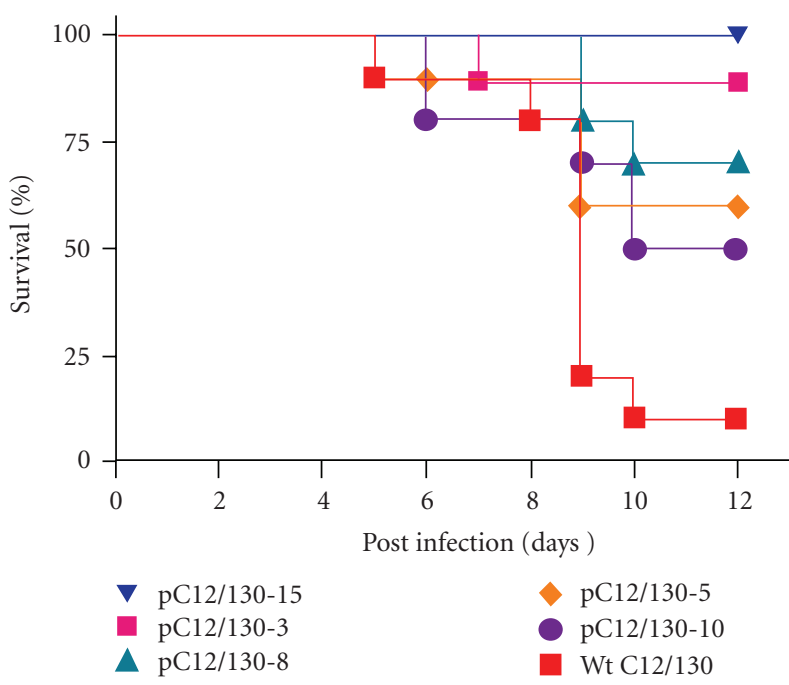

(b)

FIGURE 2: Survival curves of birds infected with C12/130 viruses. Cumulative percentage of survival of (a) genetically distinct lines of birds challenged with wild-type C12/130 virus during the 60-day experimental period $(n=10)$, and (b) RIR chicks infected with wild-type $\mathrm{C} 12 / 130$ virus and the reconstituted viruses from $\mathrm{pC} 12 / 130-3$, pC12/130-5, pC12/130-8, pC12/130-10, and pC12/130-15 during the 12-day experimental period $(n=12)$.

by qPCR from 14 days after infection of their cohorts; only those housed with the wild-type infected birds became infected with MD (data not shown).

3.4. Detection of Viral Antigen in the Brain of C12/130 VirusInfected Birds. Previously, we have reported the detection of viral antigens in brain lesions of birds infected with C121/30 virus [35]. Similar reports on the detection of virusinfected cells have also been published in birds infected with $\mathrm{vv}+\mathrm{MDV}$ strains such as 648A [40], suggesting that the infiltration of virus-infected cells into the brain is a characteristic feature of hypervirulent MDV strains. We wanted to examine 


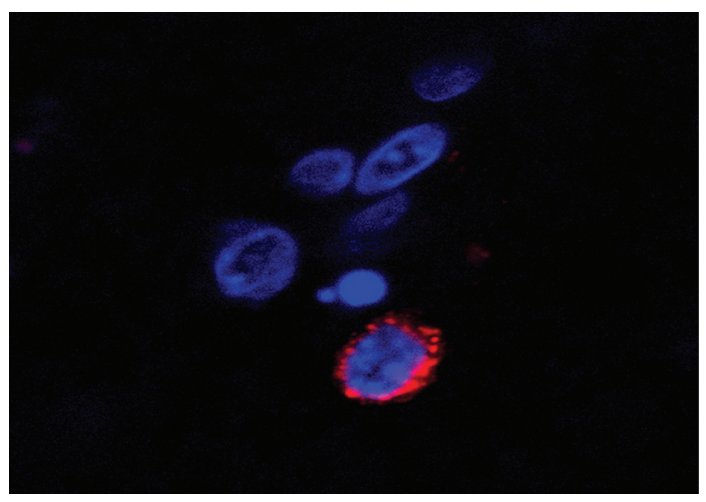

(a)

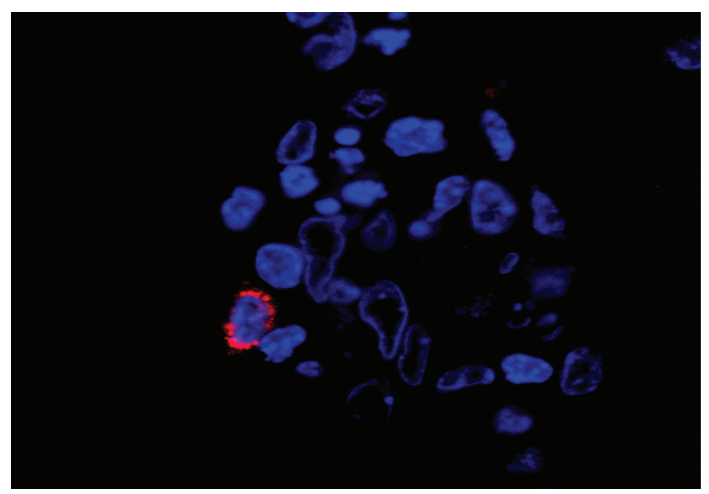

(b)

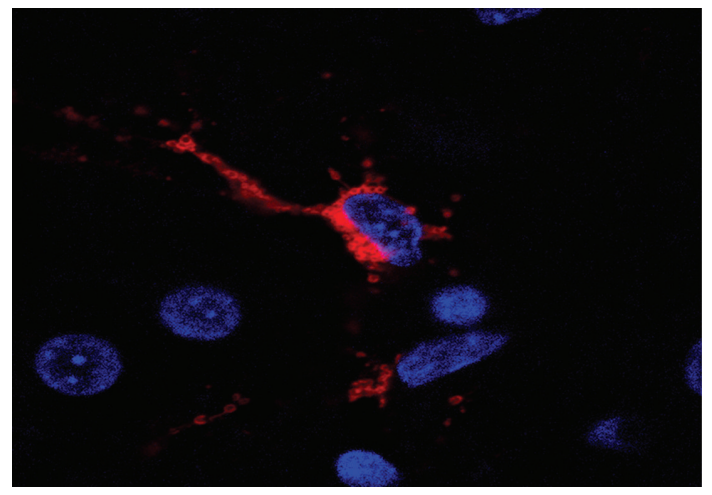

(c)

Figure 3: Confocal immunofluorescence images of brain tissues stained with MDV pp38-specific monoclonal antibody BD1. Brain tissues from birds infected with (a) wild-type C12/130, (b) pC12/130-10, and (c) pC12/130-15 viruses. The brain tissues were taken eight days postinfection showing infected cells stained with pp38- (red) and DAPI- (blue) stained nuclei.

whether the $\mathrm{C} 12 / 130$ viruses reconstituted from the BAC clones would infiltrate the brain of birds and express viral antigens. For this, we examined the brain samples from birds infected with the wild-type $\mathrm{C} 12 / 130$ or the viruses reconstituted from the pC12/130-10 and pC12/130-15 clones for viral antigen pp38 by immunofluorescence staining using the specific antibody BD1. Viral antigen pp38 could be detected in the brain tissues of birds infected with the wild-type as well as the two BAC-derived viruses (Figure 3). Interestingly, pp38 was also detected in the brain of birds infected with C12/130-15 virus although they did not develop any early cytolytic disease. These results suggested that the infiltration of infected cells is not necessarily associated with the acute cytolytic disease although we did not attempt to quantitate the levels of the infiltration of infected cells into the brain.

Our study presents several interesting highlights. At the outset, this is the first report on the cloning of the fulllength genome of a hypervirulent European MDV isolate as infectious BAC clones. Moreover, induction of cytolytic disease by some of the BAC-derived viruses demonstrates that the cloned viruses retain the biological characteristics of the parent virus. Interestingly, the study also showed that no viruses from any of the individual clones were able to induce the disease to the same levels as the wildtype virus. Similar observations have also been made with BAC clones of oncogenic MDV strains such as RB-1B [4]. Such differences may be due to the quasispecies nature $[20,21]$ that could provide selective fitness advantages for more virulent strains in the wild-type virus. Alternatively, the cloning steps involved in the construction of the BAC may selectively disadvantage the more virulent viruses in the pool. Our study shows that individual viral genomes, despite originating from a single population of parental virus, can differ in virulence in disease models. In fact, the isolation of BAC clones pC12/130-10 and pC12/130-15 that behave at either end of the disease spectrum, with respect to the induction of early cytolytic disease and mortality, provides a great opportunity to identify the molecular virulence determinants by direct sequence analysis as well as by the application of reverse genetics.

\section{Conclusions}

We report here the cloning of the full-length genome of a hypervirulent UK MDV strain C12/130 that induces acute cytolytic disease with brain lesions. The ability of these infectious BAC clones to reconstitute viruses that have very similar biological characteristics to the parent wild-type virus provides the opportunity to carry out investigations into the identification of molecular determinants associated with the distinct features of this hypervirulent strain to induce acute cytolytic disease. We also show that different $\mathrm{BAC}$ clones that represent individual genomes of viruses, despite originating from a single source, differed in virulence. The construction of BAC clones of these important viral pathogens that differ in virulence offers the opportunity to identify viral determinants associated with acute cytolytic disease and neuronal pathogenicity.

\section{Acknowledgments}

This work was supported by grants from the Department of Environment, Food and Rural Affairs (Defra) and the Biotechnology and Biological Sciences Research Council (BBSRC), United Kingdom. L. P. Smith and L. J. Petherbridge contributed equally to the paper. 


\section{References}

[1] M. Messerle, I. Crnkovic, W. Hammerschmidt, H. Ziegler, and U. H. Koszinowski, "Cloning and mutagenesis of a herpesvirus genome as an infectious bacterial artificial chromosome," Proceedings of the National Academy of Sciences of the United States of America, vol. 94, no. 26, pp. 14759-14763, 1997.

[2] A. McGregor and M. R. Schleiss, "Recent advances in Herpesvirus genetics using bacterial artificial chromosomes," Molecular Genetics and Metabolism, vol. 72, no. 1, pp. 8-14, 2001.

[3] D. Schumacher, B. K. Tischer, W. Fuchs, and N. Osterrieder, "Reconstitution of Marek's disease virus serotype 1 (MDV1) from DNA cloned as a bacterial artificial chromosome and characterization of a glycoprotein B-negative MDV-1 mutant," Journal of Virology, vol. 74, no. 23, pp. 11088-11098, 2000.

[4] L. Petherbridge, A. C. Brown, S. J. Baigent et al., "Oncogenicity of virulent Marek's disease virus cloned as bacterial artificial chromosomes," Journal of Virology, vol. 78, no. 23, pp. 1337613380, 2004.

[5] L. Petherbridge, K. Howes, S. J. Baigent et al., "Replicationcompetent bacterial artificial chromosomes of Marek's disease virus: novel tools for generation of molecularly defined herpesvirus vaccines," Journal of Virology, vol. 77, no. 16, pp. 8712-8718, 2003.

[6] S. J. Baigent, L. J. Petherbridge, L. P. Smith, Y. Zhao, P. M. Chesters, and V. K. Nair, "Herpesvirus of turkey reconstituted from bacterial artificial chromosome clones induces protection against Marek's disease," Journal of General Virology, vol. 87, no. 4, pp. 769-776, 2006.

[7] S. M. Singh, S. J. Baigent, L. J. Petherbridge, L. P. Smith, and V. K. Nair, "Comparative efficacy of BAC-derived recombinant SB-1 vaccine and the parent wild type strain in preventing replication, shedding and disease induced by virulent Marek's disease virus," Research in Veterinary Science, vol. 89, no. 1, pp. 140-145, 2010.

[8] L. Petherbridge, H. Xu, Y. Zhao et al., "Cloning of Gallid herpesvirus 3 (Marek's disease virus serotype-2) genome as infectious bacterial artificial chromosomes for analysis of viral gene functions," Journal of Virological Methods, vol. 158, no. 1-2, pp. 11-17, 2009.

[9] B. K. Tischer, D. Schumacher, M. Beer et al., "A DNA vaccine containing an infectious Marek's disease virus genome can confer protection against tumorigenic Marek's disease in chickens," Journal of General Virology, vol. 83, no. 10, pp. 2367-2376, 2002.

[10] M. Niikura, J. Dodgson, and H. Cheng, "Direct evidence of host genome acquisition by the alphaherpesvirus Marek's disease virus," Archives of Virology, vol. 151, no. 3, pp. 537-549, 2006.

[11] R. F. Silva, J. R. Dunn, H. H. Cheng, and M. Niikura, "A MEQdeleted marek's disease virus cloned as a bacterial artificial chromosome is a highly efficacious vaccine," Avian Diseases, vol. 54, no. 2, pp. 862-869, 2010.

[12] A. C. Brown, S. J. Baigent, L. P. Smith et al., "Interaction of MEQ protein and C-terminal-binding protein is critical for induction of lymphomas by Marek's disease virus," Proceedings of the National Academy of Sciences of the United States of America, vol. 103, no. 6, pp. 1687-1692, 2006.

[13] A. C. Brown, L. P. Smith, L. Kgosana, S. J. Baigent, V. Nair, and M. J. Allday, "Homodimerization of the Meq viral oncoprotein is necessary for induction of T-cell lymphoma by Marek's disease virus," Journal of Virology, vol. 83, no. 21, pp. 1114211151, 2009.
[14] S. Trapp, M. S. Parcells, J. P. Kamil et al., "A virus-encoded telomerase RNA promotes malignant $\mathrm{T}$ cell lymphomagenesis," Journal of Experimental Medicine, vol. 203, no. 5, pp. 1307-1317, 2006.

[15] R. L. Witter, "Marek's disease vaccines-past, present and future (Chicken vs virus-a battle of the centuries)," in Current Progress on Marek's Disease Research, K.A. Schat et al., Ed., pp. 1-9, American Association of Avian Pathologists, Kennett Square, Pa, USA, 2001.

[16] V. Nair, "Evolution of Marek's disease-a paradigm for incessant race between the pathogen and the host," Veterinary Journal, vol. 170, no. 2, pp. 175-183, 2005.

[17] R. L. Witter, “Increased virulence of Marek's disease virus field isolates," Avian Diseases, vol. 41, no. 1, pp. 149-163, 1997.

[18] R. L. Witter, "The changing landscape of Marek's disease," Avian Pathology, vol. 27, supplement 1, pp. S46-S53, 1998.

[19] R. L. Witter, B. W. Calnek, C. Buscaglia, I. M. Gimeno, and K. A. Schat, "Classification of Marek's disease viruses according to pathotype: philosophy and methodology," Avian Pathology, vol. 34, no. 2, pp. 75-90, 2005.

[20] S. J. Spatz, C. Rue, D. Schumacher, and N. Osterrieder, "Clustering of mutations within the inverted repeat regions of a serially passaged attenuated gallid herpesvirus type 2 strain," Virus Genes, vol. 37, no. 1, pp. 69-80, 2008.

[21] S. J. Spatz and R. F. Silva, "Polymorphisms in the repeat long regions of oncogenic and attenuated pathotypes of Marek's disease virus 1," Virus Genes, vol. 35, no. 1, pp. 41-53, 2007.

[22] A. Barrow and K. Venugopal, "Molecular characteristics of very virulent European MDV isolates," Acta Virologica, vol. 43, no. 2-3, pp. 90-93, 1999.

[23] K. Venugopal, "Pathogenicity of an unusual highly virulent Marek's disease virus isolated in the United Kingdom," in Proceedings of the 5th International symposium on Marek's disease, Michigan State University, 1996.

[24] I. Kross, P. J. Davis, and R. W. Shilleto, "Isolation of highly cytolytic MDV strains from Germany and Spain," Avian Pathology, vol. 27, no. 3, pp. 313-315, 1998.

[25] A. D. Barrow, S. C. Burgess, S. J. Baigent, K. Howes, and V. K. Nair, "Infection of macrophages by a lymphotropic herpesvirus: a new tropism for Marek's disease virus," Journal of General Virology, vol. 84, no. 10, pp. 2635-2645, 2003.

[26] S. J. Spatz and C. A. Rue, "Sequence determination of a mildly virulent strain (CU-2) of Gallid herpesvirus type 2 using 454 pyrosequencing," Virus Genes, vol. 36, no. 3, pp. 479-489, 2008.

[27] L. Petherbridge, A. C. Brown, S. J. Baigent et al., "Oncogenicity of virulent Marek's disease virus cloned as bacterial artificial chromosomes," Journal of Virology, vol. 78, no. 23, pp. 1337613380, 2004.

[28] L. Petherbridge, K. Howes, S. J. Baigent et al., "Replicationcompetent bacterial artificial chromosomes of Marek's disease virus: novel tools for generation of molecularly defined herpesvirus vaccines," Journal of Virology, vol. 77, no. 16, pp. 8712-8718, 2003.

[29] D. Schumacher, B. K. Tischer, W. Fuchs, and N. Osterrieder, "Reconstitution of Marek's disease virus serotype 1 (MDV1) from DNA cloned as a bacterial artificial chromosome and characterization of a glycoprotein B-negative MDV-1 mutant," Journal of Virology, vol. 74, no. 23, pp. 11088-11098, 2000.

[30] J. Sambrook and D.W. Russell, Molecular Cloning: A Laboratory Manual, vol. 1, Cold Spring Harbor Laboratory, New York, NY, USA, 2001.

[31] D. G. Altman, Practical Statistics for Medical Research, Chapman \& Hall, London, UK, 1991. 
[32] D. Li, P. F. Green, M. A. Skinner, C. Jiang, and N. Ross, "Use of recombinant pp38 antigen of Marek's disease virus to identify serotype 1-specific antibodies in chicken sera by Western blotting," Journal of Virological Methods, vol. 50, no. 1-3, pp. 185-196, 1994.

[33] A. Barrow and K. Venugopal, "Molecular characteristics of very virulent European MDV isolates," Acta Virologica, vol. 43, no. 2-3, pp. 90-93, 1999.

[34] A. D. Barrow, S. C. Burgess, S. J. Baigent, K. Howes, and V. K. Nair, "Infection of macrophages by a lymphotropic herpesvirus: a new tropism for Marek's disease virus," Journal of General Virology, vol. 84, no. 10, pp. 2635-2645, 2003.

[35] A. D. Barrow, S. C. Burgess, K. Howes, and V. K. Nair, "Monocytosis is associated with the onset of leukocyte and viral infiltration of the brain in chickens infected with the very virulent Marek's disease virus strain C12/130," Avian Pathology, vol. 32, no. 2, pp. 183-191, 2003.

[36] A. D. Barrow, S. C. Burgess, K. Howes, and K. Venugopal, "Invasion of avian macrophages by highly virulent Marek's disease virus strain C12/130 represents a "tropic" shift in the pathogenesis," in Current Progress on Marek's Disease Research, K. A. Schat, R. W. Morgan, M. S. Parcells, and J. L. Spencer, Eds., pp. 63-67, American Association of Avian Pathologists, Kennett Square, Pa, USA, 2001.

[37] I. M. Gimeno et al., "Chronological study of brain alterations induced by a very virulent plus (vv1) strain of Marek's disease virus (MDV)," in Current Progress on Marek's Disease Research, K. A. Schat, R. W. Morgan, M. S. Parcells, and J. L. Spencer, Eds., pp. 21-26, American Association of Avian Pathologists, Kennett Square, Pa, USA, 2001.

[38] K. W. Jarosinski, B. L. Njaa, P. H. O’Connell, and K. A. Schat, "Pro-inflammatory responses in chicken spleen and brain tissues after infection with very virulent plus Marek's disease virus," Viral Immunology, vol. 18, no. 1, pp. 148-161, 2005.

[39] I. M. Gimeno, R. L. Witter, and U. Neumann, "Neuropathotyping: a new system to classify Marek's disease virus," Avian Diseases, vol. 46, no. 4, pp. 909-918, 2002.

[40] I. M. Gimeno, R. L. Witter, H. D. Hunt, L. F. Lee, S. M. Reddy, and U. Neumann, "Marek's disease virus infection in the brain: virus replication, cellular infiltration, and major histocompatibility complex antigen expression," Veterinary Pathology, vol. 38, no. 5, pp. 491-503, 2001. 

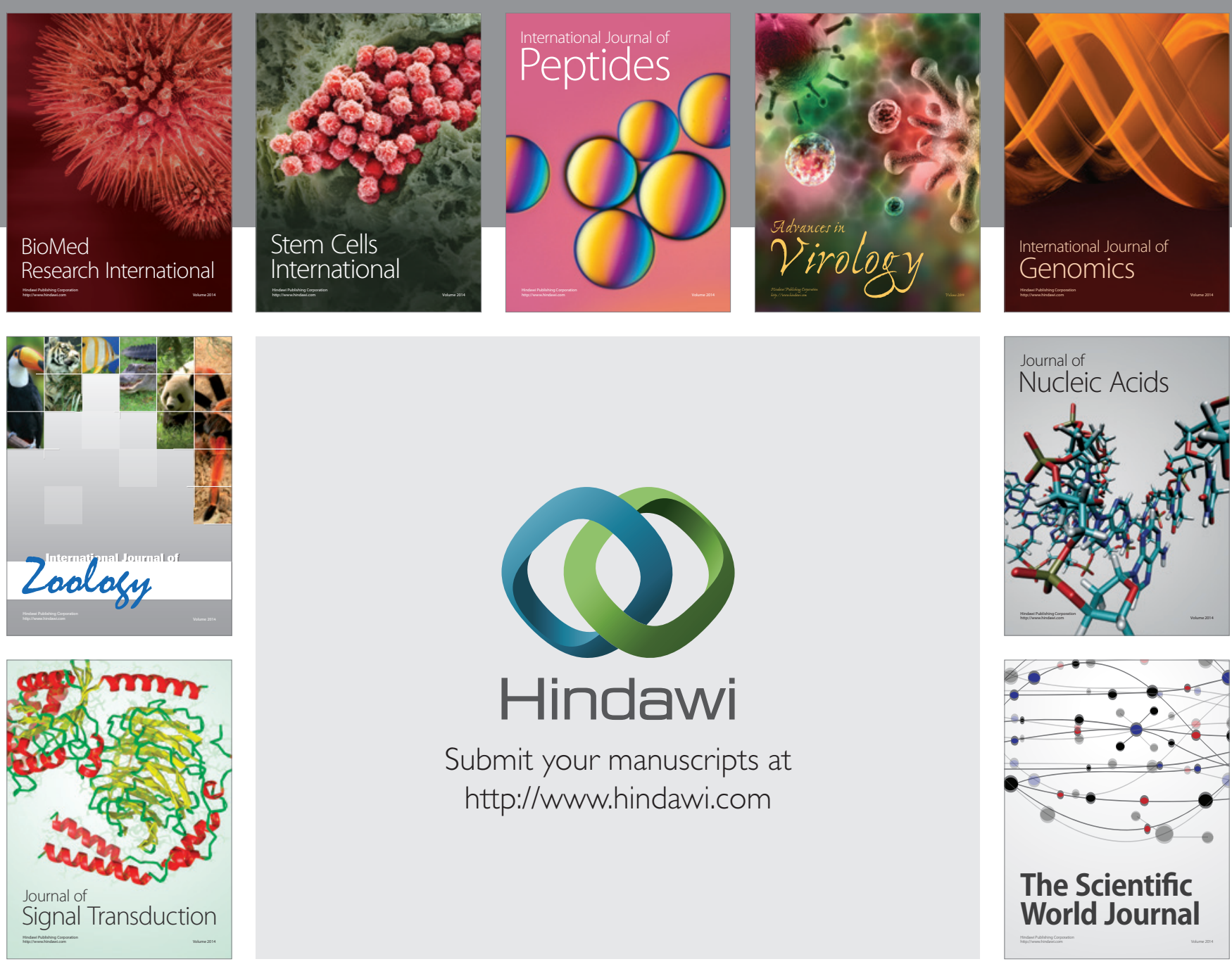

Submit your manuscripts at

http://www.hindawi.com
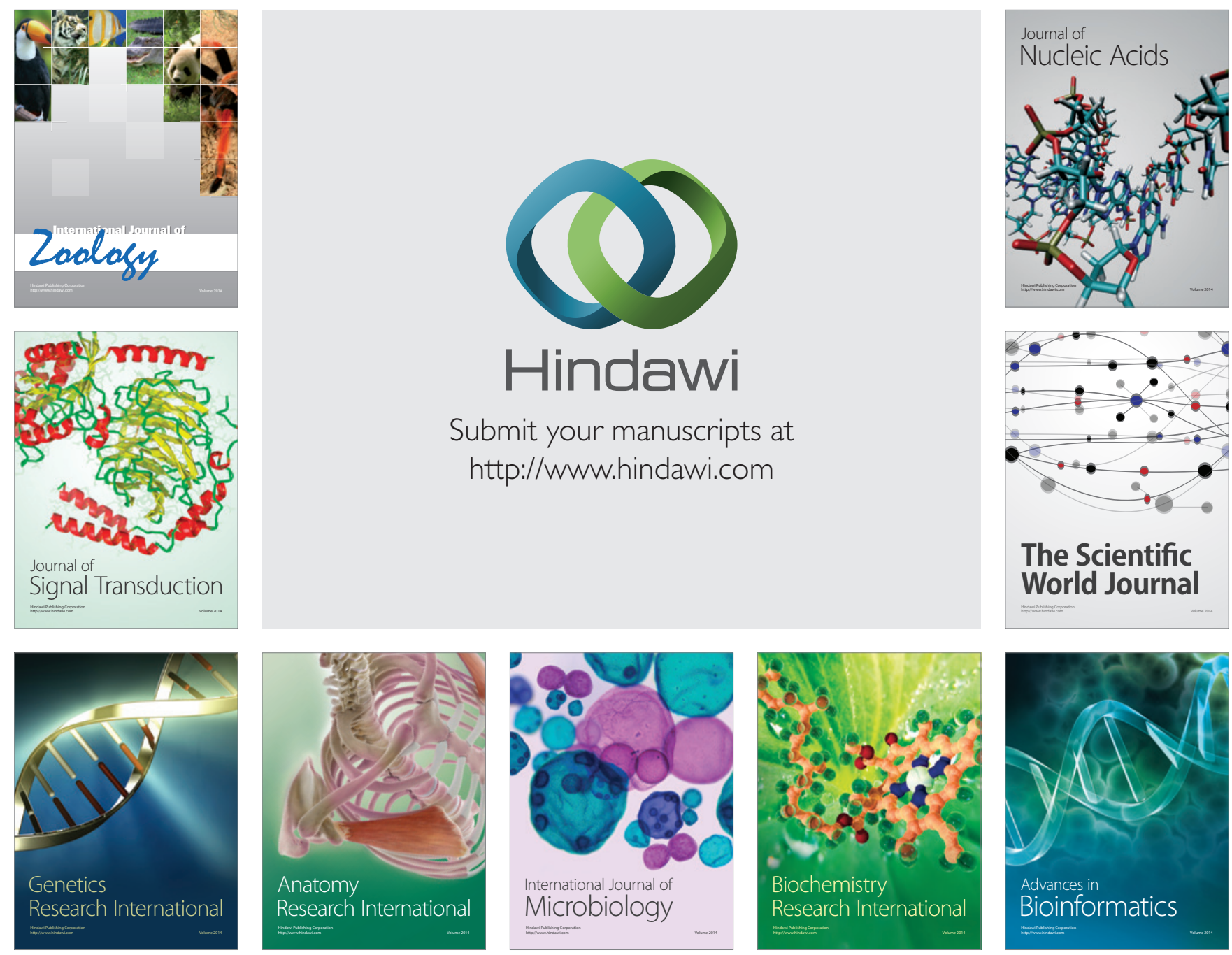

The Scientific World Journal
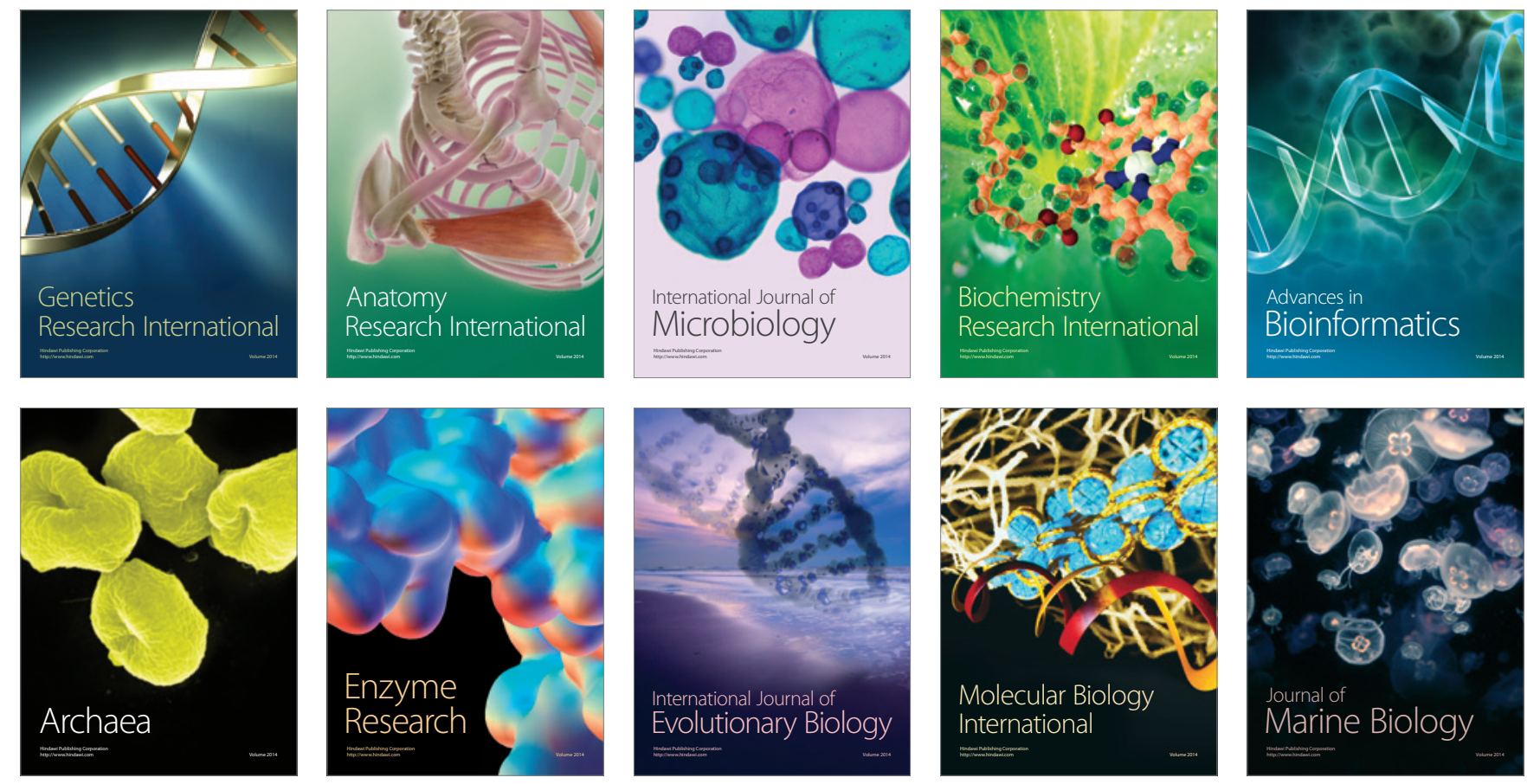